Anton Hiersche

Sowjetliteratur

und wissenschaftlich-technische Revolution 


\title{
Literatur und Gesellschaft
}

\author{
Herausgegeben von der \\ Akademie der Wissenschaften der DDR \\ Zentralinstitut für Literaturgeschichte
}


Anton Hiersche

Sowjetliteratur

\section{und \\ wissenschaftlich-technische \\ Revolution}

Akademie-Verlag Berlin

1976 
Erschienen im Akademie-Verlag, 108 Berlin, Leipziger Straße 3-4

(c) 1975 by Akademie-Verlag, Berlin

Lizenznummer : $202 \cdot 100 / 184 / 75$

Gesamtherstellung: VEB Druckerei ,Thomas Müntzer“,

582 Bad Langensalza/DDR

Bestellnummer: $7526421(2150 / 33) \cdot$ LSV 8036

Printed in GDR

EVP 8,50 